\title{
Fetal Alcohol Spectrum Disorders: Fixing Our Aim to Aim for the Fix
}

\author{
Larry Burd ${ }^{1, *}$ and Svetlana Popova ${ }^{2,3,4}$ \\ 1 North Dakota Fetal Alcohol Syndrome Center, Department of Pediatrics, University of North Dakota School of \\ Medicine and Health Sciences, Pediatric Therapy Services, Altru Health System, Grand Forks, ND 58202, USA \\ 2 Institute for Mental Health Policy Research \& Campbell Family Mental Health Research Institute, \\ Centre for Addiction and Mental Health, (CAMH), Toronto, ON M6J 1H4, Canada; Lana.Popova@camh.ca \\ 3 Epidemiology Division, Office of Global Public Health Education \& Training, \\ Dalla Lana School of Public Health, University of Toronto, Toronto, ON M5S 1A1, Canada \\ 4 Factor-Inwentash Faculty of Social Work, University of Toronto, Toronto, ON M5S 1A1, Canada \\ * Correspondence: larry.burd@UND.edu
}

Received: 23 September 2019; Accepted: 12 October 2019; Published: 18 October 2019

We, as editors of this special issue on Fetal Alcohol Spectrum Disorders (FASD), are proud to present eleven papers [1-11]. These studies focused on prevention, systems development, clinical practice, and public policy. These are most welcome enhancements to the scientific evidence base on FASD.

FASD continues to be an enigma. Prevalence rates are high, but rates of diagnosis are low. FASD poses a huge clinical and public health burden, yet it receives only modest attention from clinicians. FASD is more prevalent than autism and providing care and interventions for individuals with FASD is more expensive. Yet these services receive only a small fraction of what is allocated for autism. FASD is potentially preventable but funding for prevention is also minimal. FASD imposes a huge burden on mental health, child welfare, and correctional systems. Yet, equivalent investments in research or clinical practice are lacking. This has been the state of FASD for decades.

In the Factsheet, presented below, we summarize the current state of FASD. We finally need to face the facts! FASD is a common disorder, which is rarely diagnosed and, as a result, nearly always treated as something else. This has consequences that are devastating for people with FASD and their families.

Four common issues are at the root of this problem.

Firstly, the belief that FASD must be diagnosed by a multidisciplinary team. FASD is common; there are 1726 to 17,810 new cases every DAY globally. Currently, we cannot diagnose even $1 \%$ of these cases. There are 11.3 MILLION affected people 18 years old or younger. Even a moment of reflection should startle us to the realization that we do not have the capacity to provide multidisciplinary evaluations for a population of this size. Even the wealthiest countries cannot provide this service. The good news is, it is not needed. Most individuals with FASD are in systems of care that with a few modest modifications can greatly improve care for people with FASD and their families.

Secondly, we now have to face the facts-in FASD - it is not the face. Most of the complexity of FASD is due to other problems. Prematurity, growth impairments, brain damage, victimization, and the inability to avoid exploitation and to live independently are the central problems.

Thirdly, Fetal Alcohol Syndrome (FAS) - the most severe and visible form of FASD is rarely diagnosed at delivery, in the neonatal intensive care nursery or during well childcare. Obstetricians, midwives, labor and delivery teams, and neonatal intensive care teams have demonstrated the ability to respond to prenatal substance exposure consequent to the opioid crisis. We need to see similar changes to improve care for infants and families impacted by prenatal alcohol exposure.

Fourthly, pediatricians, family doctors, early intervention teams, social workers, the judiciary, and mental health providers see children with FASD. We need a clinical diagnosis that can be 
implemented in these settings. The phenotype of FASD is expressed in these systems. Currently, care provided by schools, psychiatrists, developmental medicine, residential care facilities, and foster care systems, are too often followed by juvenile corrections, more mental health concerns, and substance use.

In contrast, FASD should be a clinical story about early intervention to prevent recurrence, interventions to prevent exposure to adverse childhood experiences (ACEs), services before, during and after foster care placements, and intensive intervention before FASD severity requires residential care and involvement with juvenile corrections.

While we do have severe problems with care provided for children and adolescents with FASD, we have far more serious problems with identification and care for adults and the elderly with FASD. Our current policies reflect the view that no one with FASD becomes elderly. In the United States and Canada alone, there are millions of undiagnosed adults and elderly people with FASD.

Existing care pathways for severe FASD, which involves growth impairments, congenital anomalies, and abnormalities of the face, are already integrated across the continuum of care in the United States and Canada. We just need to identify the etiology. It is the common and typical manifestation of FASD that we are missing. It is brain damage, exposure to early and often severe adversity, and a lack of anticipatory intervention that are our current problems. FASD is a disorder of development-a developmental disability with onset at birth. It is a mental health disorder with high rates of comorbidity, which affects parents, caretakers, schools, juvenile corrections, residential care systems, and society. In FASD, diagnosis-informed care should be our mantra. We need to accept that it is common, it is costly, it is often severe, and it is rarely diagnosed. As a result, people with FASD are often misdiagnosed and provided suboptimal treatment.

What is the solution?

- Develop universal clinical diagnostic guidelines for clinicians who care for people with FASD. It must be brief and composed of the clinical language that these clinicians use in their day-to-day practice. It must be included in diagnostic nomenclatures and it must be a reimbursable diagnosis (a diagnosis with billing codes). The diagnosis must enhance our capacity for early diagnosis before exposure to ACEs and the avalanche of secondary disabilities, which exacerbate the overall severity of FASD and increase both the burden and cost of care. Having a diagnosis of FASD is a protective factor.

- Undergraduate and postgraduate medical education and other health care provider curriculum, assessment, and accreditation must include the risks of prenatal alcohol use and FASD. Also, we need to obligate medical doctors, family physicians, and obstetricians to ask women of childbearing age and pregnant women about their alcohol use in order to detect women whose children are at risk for FASD. This should lead to universal screening for alcohol use and provision of brief interventions and referral to treatment, where appropriate, to all pregnant women and women of childbearing age.

- We should provide postpartum support for new mothers, especially mothers of children with FASD, in order to prevent intergenerational re-occurrence of FASD.

- Affected people and their families need to access to timely and diagnosis-informed interventions and ongoing support to people with FASD and their families. We need to develop surveillance systems for FASD and prenatal alcohol exposure in order to monitor trends in incidence and prevalence and to evaluate the effectiveness of our initiatives and interventions.

- We need to better educate our population including children and adolescents (both girls and boys, women and men) about the detrimental consequences of alcohol use during pregnancy. We must inform all women of childbearing age that they should abstain from any type of alcohol use during their entire pregnancy and even when they are trying to get pregnant.

- Finally, our target should be zero alcohol consumption during pregnancy and thus, zero new FASD cases. Meeting this target is possible, if we act now. The WHO's Global strategy to reduce 
the harmful use of alcohol [12] and the WHO's Global action plan for the prevention and control of non-communicable diseases 2013-2020 [13] highlight ten policy areas for multi-sectoral national action to protect the health of populations and reduce the alcohol-attributable disease burden, including FASD.

To conclude, in FASD, the facts provide a face for the disorder and it rarely includes the face (Table 1). The phenotype is mostly behind the face. FASD is mostly a disorder of brain damage and the developmental consequences of brain dysfunction that result in impairments.

Table 1. Fetal alcohol spectrum disorders (FASD): A 2019 Fact Sheet.

\begin{tabular}{|c|c|c|}
\hline \multicolumn{2}{|l|}{ Prevalence of Alcohol Use in Pregnancy } & \multirow{2}{*}{$\begin{array}{l}\text { Reference } \\
{[14]}\end{array}$} \\
\hline Early pregnancy alcohol use (USA) & $50 \%$ & \\
\hline Alcohol use at end of pregnancy (USA) & $1 \%-7 \%$ & {$[14]$} \\
\hline Alcohol use at any time of pregnancy (globally) & $10 \%$ & [15] \\
\hline Binge drinking during pregnancy (globally) & $\begin{array}{l}10.7 \% \text { to } 31.0 \% \text { (in Europe } \\
\text { and Africa, respectively) }\end{array}$ & [16] \\
\hline $\begin{array}{l}\text { Women drinking during pregnancy identified by prenatal care } \\
\text { providers (USA) }\end{array}$ & $1 \%-3 \%$ & [17] \\
\hline Women consuming alcohol on the same day they give birth (USA) & 34,285 & [18] \\
\hline Alcohol withdrawal in newborn (globally) & $\begin{array}{l}\text { Rarely recognized; only } 1 \\
\text { case reported every } 10 \text { years }\end{array}$ & [18] \\
\hline \multicolumn{3}{|c|}{ Neonatal Risks Associated with Prenatal Alcohol Exposure (PAE) } \\
\hline Developing FASD among exposed children & 1 in 13 & [19] \\
\hline Risk for stillbirth & $40 \%$ higher & [20] \\
\hline $\begin{array}{l}\text { PAE at the end of pregnancy and risk of SIDS for siblings of child } \\
\text { with FASD }\end{array}$ & $10.2 \times$ higher & [21] \\
\hline $\begin{array}{l}\text { PAE at the end of pregnancy and risk of death from infectious } \\
\text { diseases for siblings of child with FASD }\end{array}$ & $13.7 \times$ higher & [21] \\
\hline Mortality risk for sibling of a child with FAS & $6.3 \times$ higher & [22] \\
\hline Risk of recurrence in families with one affected child (FASD) & $77 \%$ higher & [23] \\
\hline \multicolumn{3}{|l|}{ Fetal Alcohol Spectrum Disorder (FASD) } \\
\hline \multicolumn{3}{|l|}{ Prevalence and Incidence Estimates } \\
\hline Newborns identified in NICU with FASD each year (USA) & $<70$ per year & [19] \\
\hline New FASD cases per day (globally) & 1726 & [24] \\
\hline \multirow{2}{*}{ New FASD cases per day (globally) } & $1 \%$ prevalence $=3562$ & [19] \\
\hline & $5 \%$ prevalence $=17,810$ & [25] \\
\hline Global FASD population: Children/youth (birth-18 years) & $11,339,820$ & See calculations ${ }^{*} 1$ \\
\hline Global FASD population: Adults with FASD (19-64 years) & $28,349,550$ & See calculations $* 2$ \\
\hline Global FASD population: Elderly with FASD (65+) & $4,409,930$ & See calculations $* 3$ \\
\hline FASD prevalence/10,000 (globally) & 62.7 & $\begin{array}{l}\text { Calculated based } \\
\text { on Reference [16] }\end{array}$ \\
\hline
\end{tabular}


Table 1. Cont.

\begin{tabular}{|c|c|c|}
\hline \multicolumn{2}{|c|}{ Prevalence of Alcohol Use in Pregnancy } & Reference \\
\hline \multicolumn{3}{|c|}{ FASD and Health and Mental Health Impairments } \\
\hline $\begin{array}{l}\text { Number of comorbid disease conditions associated with FASD } \\
\text { (globally) }\end{array}$ & Over 400 & [26] \\
\hline Risk of child or adolescent psychosis & $24.5 \times$ higher & [27] \\
\hline Risk of intellectual disability & $23 \times$ higher & [27] \\
\hline Risk of ADHD & $10 \times$ higher & [27] \\
\hline Risk of anxiety disorder & $11 \times$ higher & [27] \\
\hline Risk of FASD if ACEs score: $2-6$ & $2.1 \times$ higher & [28] \\
\hline Risk of FASD if ACEs score: $7-10$ & $8.1 \times$ higher & [28] \\
\hline \multicolumn{3}{|l|}{ Economic Cost } \\
\hline Annual cost of care per child (globally) & $\$ 22,810$ & [29] \\
\hline Annual cost of care per adult (globally) & $\$ 24,308$ & [29] \\
\hline Lifetime cost of care per diagnosed individual by age 43 & Over $\$ 1$ million & $\begin{array}{l}\text { Calculated based } \\
\text { on }{ }^{*}\end{array}$ \\
\hline \multicolumn{3}{|l|}{ Special Sub-Populations } \\
\hline Children/youth with FASD in foster care placement & $\begin{array}{l}32 \%-40 \% \text { higher than in } \\
\text { general population }\end{array}$ & [30] \\
\hline Children/youth with FASD in special education & $\begin{array}{l}10 \times \text { higher than in general } \\
\text { population }\end{array}$ & [30] \\
\hline Children/youth with FASD in Canadian juvenile corrections & $\begin{array}{l}19 \times \text { higher risk of } \\
\text { incarceration }\end{array}$ & [31] \\
\hline Diagnosed with FASD in adult prison & $0.0009 \%$ & [32] \\
\hline Undiagnosed/misdiagnosed in adult prison & $99.9 \%$ & [32] \\
\hline \multicolumn{3}{|l|}{ Mortality Rates } \\
\hline Individuals with FASD & $4.3 \times$ higher & $\begin{array}{l}\text { Calculated based } \\
\text { on References } \\
{[21,22]}\end{array}$ \\
\hline Siblings of individuals with FASD & $5.3 \times$ higher & [21] \\
\hline Birth mother of individual with FASD & $44.8 \times$ higher & [33] \\
\hline \multicolumn{3}{|c|}{ Global Diagnostic Demand and Capacity } \\
\hline FASD diagnostic demand & $14,560 /$ day & [19] \\
\hline FASD diagnostic capacity: NICU & 30/day & [19] \\
\hline FASD diagnostic capacity: Children/youth & 200-400/day & [19] \\
\hline FASD diagnostic capacity: Adults & 100/day & [19] \\
\hline FASD diagnostic capacity: Elderly & 10/day & $\begin{array}{l}\text { Calculated based } \\
\text { on Reference [19] }\end{array}$ \\
\hline FASD diagnostic capacity: Juvenile corrections & 30-50/day & [19] \\
\hline FASD diagnostic capacity: Adult corrections & 30/day & [19] \\
\hline$\%$ of people with FASD diagnosed each year & $<1 \%$ & $\begin{array}{l}\text { Calculated based } \\
\text { on Reference [19] }\end{array}$ \\
\hline Diagnostic capacity using current FAS phenotype & Only $2 \%$ of FASD & $\begin{array}{l}\text { Calculated based } \\
\text { on Reference [19] }\end{array}$ \\
\hline
\end{tabular}

ACEs: adverse childhood experiences; ADHD: attention deficit hyperactivity disorder; FAS: fetal alcohol syndrome; NICU: neonatal intensive care unit; SIDS: sudden infant death syndrome. * ${ }^{*}$. New cases per year $[16,19]=1726$ per day $\times 365=629,990$ cases per year $\times 18$ years $=11,339,820 . * 2$. New cases per year $[16,19]=1726$ per day $\times 365=629,990$ cases per year $\times 45$ years $=28,349,550$. $* 3$. New cases per year $[16,19]=1726$ per day $\times 365=629,990$ cases per year $\times$ 7 years (from 65 to 71 years) $=4,409,930 . * 4$. Annual cost of care for children and youth $=\$ 22,810$ (birth through 20) and cost for adults $=\$ 24,308$ (from 21 and up) [19]; $(\$ 22,810 \times 20$ years $)+(\$ 24,308 \times 23$ years $)=\$ 1,015,284$.

So, let us face it, we need change. 
Funding: This research received no external funding.

Conflicts of Interest: The authors declare no conflict of interest.

\section{References}

1. Adebiyi, B.O.; Mukumbang, F.C.; Erasmus, C. The Distribution of Available Prevention and Management Interventions for Fetal Alcohol Spectrum Disorder (2007 to 2017): Implications for Collaborative Actions. Int. J. Environ. Res. Public Health 2019, 16, 2244. [CrossRef] [PubMed]

2. Bagley, K.; Badry, D. How Personal Perspectives Shape Health Professionals' Perceptions of Fetal Alcohol Spectrum Disorder and Risk. Int. J. Environ. Res. Public Health 2019, 16, 1936. [CrossRef] [PubMed]

3. Brown, J.; Harr, D. Perceptions of Fetal Alcohol Spectrum Disorder (FASD) at a Mental Health Outpatient Treatment Provider in Minnesota. Int. J. Environ. Res. Public Health 2018, 16, 16. [CrossRef] [PubMed]

4. Bukiya, A.N. Fetal Cerebral Artery Mitochondrion as Target of Prenatal Alcohol Exposure. Int. J. Environ. Res. Public Health 2019, 16, 1586. [CrossRef] [PubMed]

5. Montag, A.C.; Romero, R.; Jensen, T.; Goodblanket, A.; Admire, A.; Whitten, C.; Calac, D.; Akshoomoff, N.; Sanchez, M.; Zacarias, M.; et al. The Prevalence of Fetal Alcohol Spectrum Disorders in An American Indian Community. Int. J. Environ. Res. Public Health 2019, 16, 2179. [CrossRef]

6. Parackal, S.; Parackal, M.; Harraway, J. Associated Factors of Drinking Prior to Recognising Pregnancy and Risky Drinking among New Zealand Women Aged 18 to 35 Years. Int. J. Environ. Res. Public Health 2019, 16, 1822. [CrossRef]

7. Poole, N.; Schmidt, R.A.; Bocking, A.; Bergeron, J.; Fortier, I. The Potential for Fetal Alcohol Spectrum Disorder Prevention of a Harmonized Approach to Data Collection about Alcohol Use in Pregnancy Cohort Studies. Int. J. Environ. Res. Public Healh 2019, 16, 2019. [CrossRef]

8. Rutman, D.; Hubberstey, C. National Evaluation of Canadian Multi-Service FASD Prevention Programs: Interim Findings from the Co-Creating Evidence Study. Int. J. Environ. Res. Public Health 2019, 16, 1767. [CrossRef]

9. Shrestha, U.; Hanson, J.; Weber, T.; Ingersoll, K. Community Perceptions of Alcohol Exposed Pregnancy Prevention Program for American Indian and Alaska Native Teens. Int. J. Environ. Res. Public Health 2019, 16, 1795. [CrossRef]

10. Lepper, L.T.; King, D.; Doll, J.; Gonzalez, S.; Mitchell, A.; Hartje, J. Partnering with the Health Professions to Promote Prevention of an Alcohol-Exposed Pregnancy: Lessons Learned from an Academic-Organizational Collaborative. Int. J. Environ. Res. Public Health 2019, 16, 1702. [CrossRef]

11. Wolfson, L.; Poole, N.; Ninomiya, M.M.; Rutman, D.; Letendre, S.; Winterhoff, T.; Finney, C.; Carlson, E.; Prouty, M.; McFarlane, A.; et al. Collaborative Action on Fetal Alcohol Spectrum Disorder Prevention: Principles for Enacting the Truth and Reconciliation Commission Call to Action \#33. Int. J. Environ. Res. Public Health 2019, 16, 1589.

12. World Health Organization. Global Strategy to Reduce the Harmful Use of Alcohol; World Health Organization: Geneva, Switzerland, 2010.

13. World Health Organization. Global Action Plan for the Prevention and Control of Noncommunicable Diseases 2013-2020; World Health Organization: Geneva, Switzerland, 2013.

14. Substance Abuse and Mental Health Data Archive. National Survey on Drug Use and Health: 10-Year Substate R-DAS (NSDUH-2002-2011). 2015; Volume 2018. Available online: https://www.datafiles.samhsa. gov/study/national-survey-drug-use-and-health-nsduh-2002-nid13623 (accessed on 15 October 2019).

15. Popova, S.; Lange, S.; Probst, C.; Gmel, G.; Rehm, J. Estimation of national, regional, and global prevalence of alcohol use during pregnancy and fetal alcohol syndrome: A systematic review and meta-analysis. Lancet Glob. Heal. 2017, 5, e290-e299. [CrossRef]

16. Popova, S.; Lange, S.; Probst, C.; Gmel, G.; Rehm, J. Global prevalence of alcohol use and binge drinking during pregnancy, and fetal alcohol spectrum disorder. Biochem. Cell Biol. 2018, 96, 237-240. [CrossRef] [PubMed]

17. Burd, L.; Hudson, L. Improving Outcomes for Families Affected by Prenatal Alcohol Exposure; Quality Improvement Center for Research-Based Infant-Toddler Court Teams: Washington, DC, USA, 2019.

18. Schaff, E.; Moreno, M.; Foster, K.; Klug, M.G.; Burd, L. What do We Know about Prevalence and Management of Intoxicated Women during Labor and Delivery? Global Pediatric Health. in press. 
19. Burd, L. So What: Practicality. In Proceedings of the 8th International Conference on FASD Research: Results and Relevance 2019, Vancouver, BC, Canada, 6-9 March 2019.

20. Aliyu, M.H.; Wilson, R.E.; Zoorob, R.; Chakrabarty, S.; Alio, A.P.; Kirby, R.S.; Salihu, H.M. Alcohol consumption during pregnancy and the risk of early stillbirth among singletons. Alcohol 2008, 42, 369-374. [CrossRef]

21. Burd, L.; Wilson, H. Fetal, infant, and child mortality in a context of alcohol use. Am. J. Med Genet. 2004, 127, 51-58. [CrossRef]

22. Burd, L.; Klug, M.; Martsolf, J. Increased sibling mortality in children with fetal alcohol syndrome. Addict. Boil. 2004, 9, 179-186. [CrossRef]

23. Clarke, M.E.; Gibbard, W.B. Overview of Fetal Alcohol Spectrum Disorders for Mental Health Professionals. Can. Child Adolesc. Psychiatry Rev. 2003, 12, 57-63.

24. Lange, S.; Probst, C.; Gmel, G.; Rehm, J.; Burd, L.; Popova, S. Global Prevalence of Fetal Alcohol Spectrum Disorder Among Children and Youth: A Systematic Review and Meta-analysis. JAMA Pediatr. 2017, 171, 948-956. [CrossRef]

25. May, P.A.; Chambers, C.D.; Kalberg, W.O.; Zellner, J.; Feldman, H.; Buckley, D.; Kopald, D.; Hasken, J.M.; $\mathrm{Xu}, \mathrm{R} . ;$ Honerkamp-Smith, G. Prevalence of fetal alcohol spectrum disorders in 4 US communities. Jama 2018, 319, 474-482. [CrossRef]

26. Popova, S.; Lange, S.; Shield, K.; Mihic, A.; E Chudley, A.; Mukherjee, R.A.S.; Bekmuradov, D.; Rehm, J. Comorbidity of fetal alcohol spectrum disorder: A systematic review and meta-analysis. Lancet 2016, 387, 978-987. [CrossRef]

27. Weyrauch, D.; Schwartz, M.; Hart, B.; Klug, M.G.; Burd, L. Comorbid mental disorders in fetal alcohol spectrum disorders: A systematic review. J. Dev. Behav. Pediatr. 2017, 38, 283-291. [CrossRef] [PubMed]

28. Kambeitz, C.; Klug, M.G.; Greenmyer, J.; Popova, S.; Burd, L. Association of adverse childhood experiences and neurodevelopmental disorders in people with fetal alcohol spectrum disorders (FASD) and non-FASD controls. BMC Pediatr. 2019, in press.

29. Greenmyer, J.R.; Klug, M.G.; Kambeitz, C.; Popova, S.; Burd, L. A Multicountry Updated Assessment of the Economic Impact of Fetal Alcohol Spectrum Disorder: Costs for Children and Adults. J. Addict. Med. 2018, 12, 466-473. [CrossRef] [PubMed]

30. Popova, S.; Lange, S.; Shield, K.; Burd, L.; Rehm, J. Prevalence of fetal alcohol spectrum disorder among special subpopulations: A systematic review and meta-analysis. Addiction 2019, 114, 1150-1172. [CrossRef] [PubMed]

31. Popova, S.; Lange, S.; Bekmuradov, D.; Mihic, A.; Rehm, J. Fetal Alcohol Spectrum Disorder Prevalence Estimates in Correctional Systems: A Systematic Literature Review. Can. J. Public Heal. 2011, 102, 336-340. [CrossRef]

32. Burd, L.; Selfridge, R.; Klug, M.; Bakko, S. Fetal alcohol syndrome in the United States corrections system. Addict. Boil. 2004, 9, 169-176. [CrossRef]

33. Li, Q.; Fisher, W.W.; Peng, C.-Z.; Williams, A.D.; Burd, L. Fetal alcohol spectrum disorders: A population based study of premature mortality rates in the mothers. Matern. Child Heal. J. 2012, 16, 1332-1337. [CrossRef] 